\title{
PERFORMANCE EVALUATION OF ZIGBEE TRANSCEIVER FOR WIRELESS BODY SENSOR SYSTEM
}

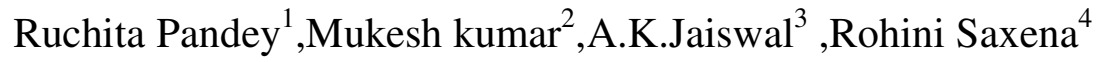 \\ ${ }^{1,2,3,4}$ (Electronics and Communication Engineering,SHIATS,U.P.,India)
}

\begin{abstract}
A cost effective impedance measurement system and a low cost transceiver device has been presented for wireless body sensor systems.The proposed device has an analog front end to measure bioimpedance and ZigBee device which provides reliable wireless communication.Bioelectric Impedance measurement enables to characterize the state of tissues.Tetrapolar method is an advance method for measuring impedance since it is a very easy and simple method for practical implementation.The principle of modified tetrapolar method and its wireless transimission through zigbee has been investigated here.Different modulation technique has been applied and it has been found that MSK based transceiver is an efficient one since it has low bit error rate and it produce constant envelope carrier signals which have no amplitude and phase varations, hence it will be a more power saving technique.
\end{abstract}

\section{KEYWORDS}

Bioimpedance,Imaginary value,Phase sensitive detector method,Real value,Tetrapolar,ZigBee.

\section{INTRODUCTION}

Many advantages of wireless transmission using ZigBee forced us to use it in various applications .One such application is in the field of medical science. Millions of people in this world suffer from healthcare issues.Hence to increase the level of medical supervision ,the concern for designing medical devices as comfortable as possible and for easy use has grown. Electrical bioimpedance measurement has been proved to be suitable for determining body composition and also for monitoring physiological parameters[1,2,3].It is more fruitful in tissue ischemia monitoring[4].Due to these facts ,Electrical bioimpedance measurement technique as wearable as possible has been proposed to reduce complication in patient's life.To observe the measurement distantly,a wireless transmission technique ZigBee can be used as it offers low power consumption ,high reliability and it is more secure technology[5,6,7,8].This technology is more simpler and cost effective than other wireless personal area networks such as Bluetooth[9].Performance of ZigBee transceiver has been analysed using different modulation techniques that are Offset Quadrature Phase Shift Keying and Minimum Shift Keying in which MSK is most promising technology[10].The characteristics ,performance and physical realization of wireless sensor communication system can be varied with varying the choice of modulation scheme.

Here for analog front end design, conventional methods and new tetrapolar method have been discussed for bioimpedance calculation in which new tetrapolar method is more accurate and has simpler design than previous old methods such as phase sensitive detection method.It excludes the use of analog demodulator .In this method that is new tetrapolar method,three voltages 
International Journal of Computer Networks \& Communications (IJCNC) Vol.6, No.3, May 2014

$\mathrm{V}_{1}, \mathrm{~V}_{2}, \mathrm{~V}_{3}$ are measured across tissue impedance,electrode impedance and across the resistor $\mathrm{R}$.The real part $\mathrm{Z}_{\text {real }}$ and imaginary part $\mathrm{Z}_{\mathrm{imag}}$ of the complex impedance can be measured by calculating modular ratios of the two input voltage to phase gain detector and phase differences of those two inputs [11].

Thus the design of real time wireless sensor system must consider the energy consumption[12],it must be reliable and cost effective.

The whole work has been organized as:section two deals with methodology which has been further divided in two subsections,first deals with different methods for bioimpedance measurement and second with the proposed zigbee technology transceiver for wireless transmission of measurement.section three deals with the result obtained for bit error rate comparision for two modulation techniques used and fourth with application of bioimpedance and zigbee technology.and lastly conclusion in section fifth.

\section{METHODOLOGY}

\subsection{ANALOG FRONT END TO MEASURE IMPEDANCE}

Some conventional methods has been described below showing how new tetrapolar method is more efficient.

\subsubsection{PHASE SENSITIVE DETECTION METHOD}

This is a fast computational method based on two phase reference coherent demodulation technique. Voltage between voltage electrode is $V_{e}(t)$

$$
V_{e}(t)=Z I \sin \left(\omega_{0} t+\theta\right),
$$

where $\mathrm{Z}$ is the magnitude of the bioimpedance, $\theta$ is the phase, and $\mathrm{I}$ is the amplitude of current provided by current source.

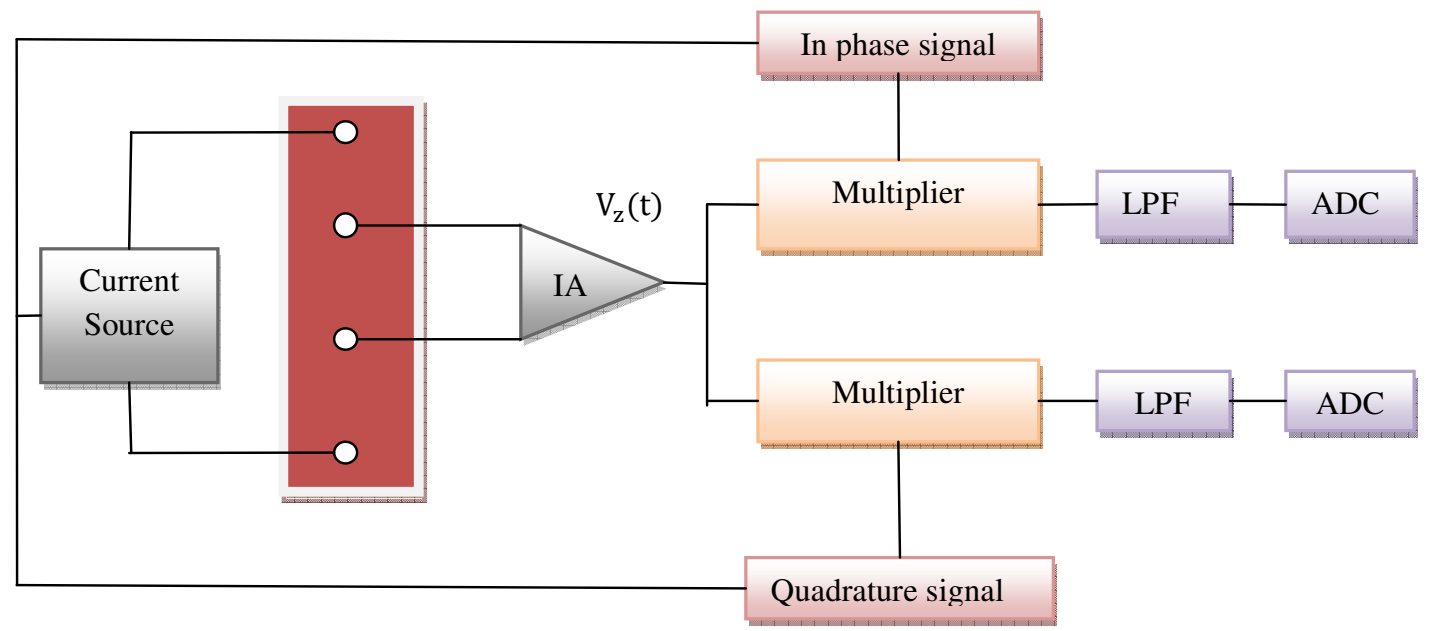

Figure 1. PSD method for measuring bioimpedance

Due to the high input impedance of the instrument amplifier IA, voltage electrodes draw practically no current, so the tissue impedance measurement is not affected by contact impedance.Output of IA $\mathrm{Vz}(\mathrm{t})$ can be represented as

$$
\mathrm{V}_{\mathrm{z}}(\mathrm{t})=\mathrm{V} \sin \left(\omega_{0} \mathrm{t}+\theta\right)
$$


International Journal of Computer Networks \& Communications (IJCNC) Vol.6, No.3, May 2014

$$
=\mathrm{V} \cdot \cos \theta \cdot \sin \omega_{0} \mathrm{t}+\mathrm{V} \cdot \sin \theta \cdot \cos \omega_{0} \mathrm{t}
$$

The multiplier multiplies $V_{z}(t)$ with inphase signal $U \sin \omega_{0} t$ and quadrature signal $U \cos \omega_{0} t$.The output obtained are passed to low pass filter and then sampled with $\mathrm{A}$ to $\mathrm{D}$ converters.Two output $\mathrm{Z}_{\text {real }}$ value is proportional to $\mathrm{V} \cos \Theta / \mathrm{I}$ and $\mathrm{Z}_{\text {imag }}$ value to $\mathrm{V} \sin \theta / \mathrm{I}$.

But use of multipliers lead to phase errors if the component are not matched.In addition the total volume of the measurement system will not be suitable for hand held design for its complexity of realization.

\subsubsection{NEW TETRAPOLAR METHOD}

It is based on the use of phase gain detector which comprises phase detector and closely matched pair of demodulating logarithmic amplifier.Resistor $\mathrm{R}$ is also added in series with two impedance,electrode and tissue impedance.The circuit includes current source,amplifiers,phase gain detector and analog to digital converter.Two electrodes are used to inject current to a biological tissue and two electrodes are used to pick up the voltage drop across it.The voltage across biological impedance,electrode impedance and across resistor $\mathrm{R}$ are amplified with the help of three identical instrument amplifiers(IA).They are then given to phase gain detector.The two DC output voltages $V_{\text {phas }}$ and $V_{\text {mag }}$ are proportional to phase difference and logarithmic ratio of the two inputs $V_{\mathrm{i} 1}$ and $V_{\mathrm{i} 2}$ respectively that is

$$
\begin{gathered}
\mathrm{V}_{\text {phas }}=\mathrm{K}_{\mathrm{p}}\left(\theta_{\mathrm{i} 1}-\theta_{\mathrm{i} 2}\right) \\
\mathrm{V}_{\text {mag }}=\mathrm{K}_{\mathrm{m}} \log \left(\frac{\mathrm{V}_{\mathrm{i} 1}}{\mathrm{~V}_{\mathrm{i} 2}}\right)
\end{gathered}
$$

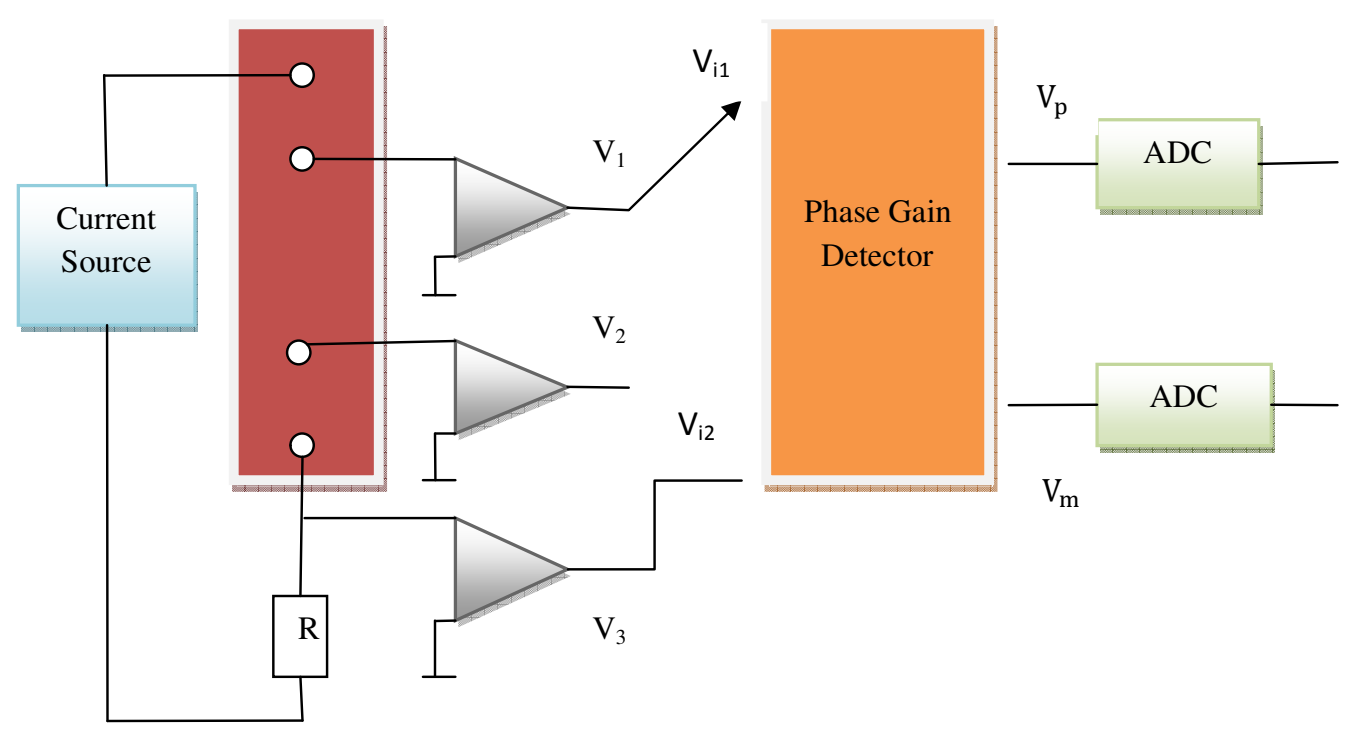

Figure 2. Tetrapolar method for bioimpedance measurement

Where $\mathrm{K}_{\mathrm{p}}$ and $\mathrm{K}_{\mathrm{m}}$ are proportionality constant, if one of the PGD input is switched to IA1 then

$$
\mathrm{V}_{\text {phas }}=\mathrm{K}_{\mathrm{p}}\left(\theta_{1}-\theta_{2}\right)
$$


International Journal of Computer Networks \& Communications (IJCNC) Vol.6, No.3, May 2014

$$
\mathrm{V}_{\text {mag }}=\mathrm{K}_{\mathrm{m}} \log \left(\frac{\mathrm{A}_{1} \mathrm{~V}_{1}}{\mathrm{~A}_{2} \mathrm{~V}_{2}}\right)
$$

If switched to IA2 then $V_{\text {phas }}$ is proportional to phase difference of $\theta_{2}$ and $\theta_{3}$ while is proportional to logarithmic ratio of $A_{2} V_{2}$ and $A_{3} V_{3}$.By getting the modular ratio $V_{1} / V_{3}$ and $V_{2} / V_{3}$,phase difference $\left(\theta_{1}-\theta_{3}\right)$ and $\left(\theta_{2}-\theta_{3}\right)$,we can calculate $Z_{\text {real }}$ and $Z_{\text {mag }}$

$$
\begin{aligned}
& \mathrm{Z}_{\text {real }}=\mathrm{R} \frac{\mathrm{V}_{1}}{\mathrm{~V}_{3}} \cos \left(\theta_{1}-\theta_{3}\right)-\mathrm{R} \frac{\mathrm{V}_{2}}{\mathrm{~V}_{3}} \cos \left(\theta_{2}-\theta_{3}\right) \\
& \mathrm{Z}_{\text {mag }}=\mathrm{R} \frac{\mathrm{V}_{1}}{\mathrm{~V}_{3}} \sin \left(\theta_{1}-\theta_{3}\right)-\mathrm{R} \frac{\mathrm{V}_{2}}{\mathrm{~V}_{3}} \sin \left(\theta_{2}-\theta_{3}\right)
\end{aligned}
$$

Hence,the overall impedance can be measured accurately.

\subsection{PROPOSED METHOD FOR WIRELESS TRANSMISSION USING ZIGBEE}

ZigBee satisfies the market needs of wireless sensor system since it is more reliable,secure and has long battery life.The block diagram for transmission of impedance data through it is shown below

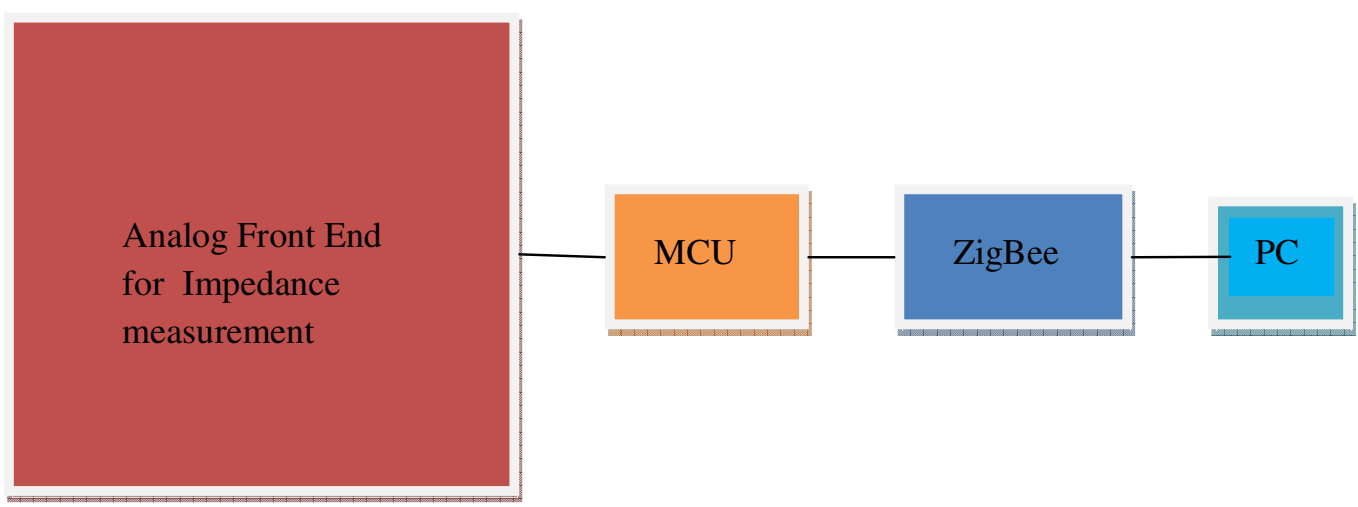

Figure 3. Wireless transmission of impedance measurement through ZigBee

\subsubsection{ALGORITHM:}

Step1: Measure the bioimpedance using tetrapolar method.

Step2: The output from phase gain detector used in tetrapolar method is fed into the microcontroller unit for analog to digital conversion.

Step3: This impedance data is transmitted to human computer interaction module through ZigBee.

Step4: The receiving module of human computer interaction module will then receives the impedance data and transfer it to monitoring system.

\subsubsection{NEED FOR ZIGBEE}

Following points supports, why there is need for using ZigBee in present scenario.

1) A number of standards need low latency and very low energy consumption for long battery lives.

2) Many wireless sensor system require low cost designing. 
Thus it can be an efficient easy technique for wireless transmission purposes.

\subsubsection{LAYERED ARCHITECTURE OF ZIGBEE}

The layered architecture for ZigBee is shown in figure 3.The architecture is divided in many layers.

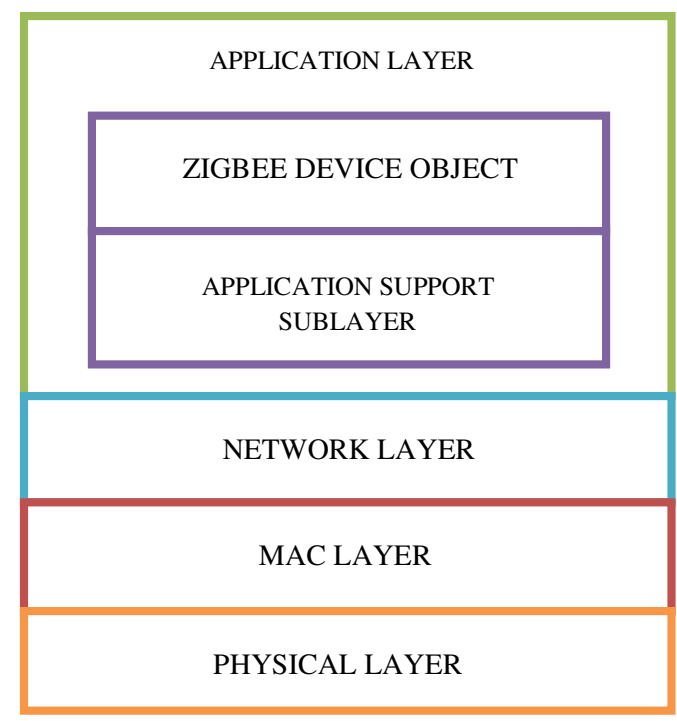

Figure 4. ZigBee Architecture

The functions for each layer can be summarized as:

1.Phsical layer is used for transmitting and receiving data.

2. With the use of Advanced Encryption Standard (AES), The MAC layer provides reliable communications.

3.The network layer is used for routing and broadcasting messages.

3)The application layer is ued for providing transport services to both ZDO and applications.

\subsubsection{FREQUENCY AND DATA RATES}

The frequency band and data rate within IEEE 802.15.4 Std or the ZigBee describes different data rates for different frequency bands,according to which different band and coverage are also mentioned below.

The following table shows the available frequency band and data rate. 
International Journal of Computer Networks \& Communications (IJCNC) Vol.6, No.3, May 2014

Table 1. Available frequency band and data rate within IEEE 802.15.4 Std.

\begin{tabular}{|c|c|c|c|}
\hline FREQUENCY & BAND & COVERAGE & DATA RATE \\
\hline $2.4 \mathrm{GHz}$ & ISM & World Wide & $250 \mathrm{Kbps}$ \\
\hline $868 \mathrm{MHz}$ & ISM & Europe & $20 \mathrm{Kbps}$ \\
\hline $915 \mathrm{MHz}$ & ISM & America & $40 \mathrm{Kbps}$ \\
\hline
\end{tabular}

\subsubsection{BLOCK DIAGRAM OF ZIGBEE TRANSCEIVER}

The design of ZigBee transmitter and receiver can be explained as shown below.

\subsubsection{Transmitter End:}

1.Following steps have been done for the transmission of data.

Firstly,Bit to symbol mapping is done for input signal.On the obtained signal then logical operation is done with PN sequence.

After it,the signal is passed to serial to parallel converter that operates using a clock,two D flipflops and one $\mathbf{J}$ flipflop.In phase and outphase data are thus obtained which when multiplied by sine wave generator,provides half sine pulse shaping.

Further after modulation of both data signals with high frequency carrier and adding them,the signal is finally transmitted. 


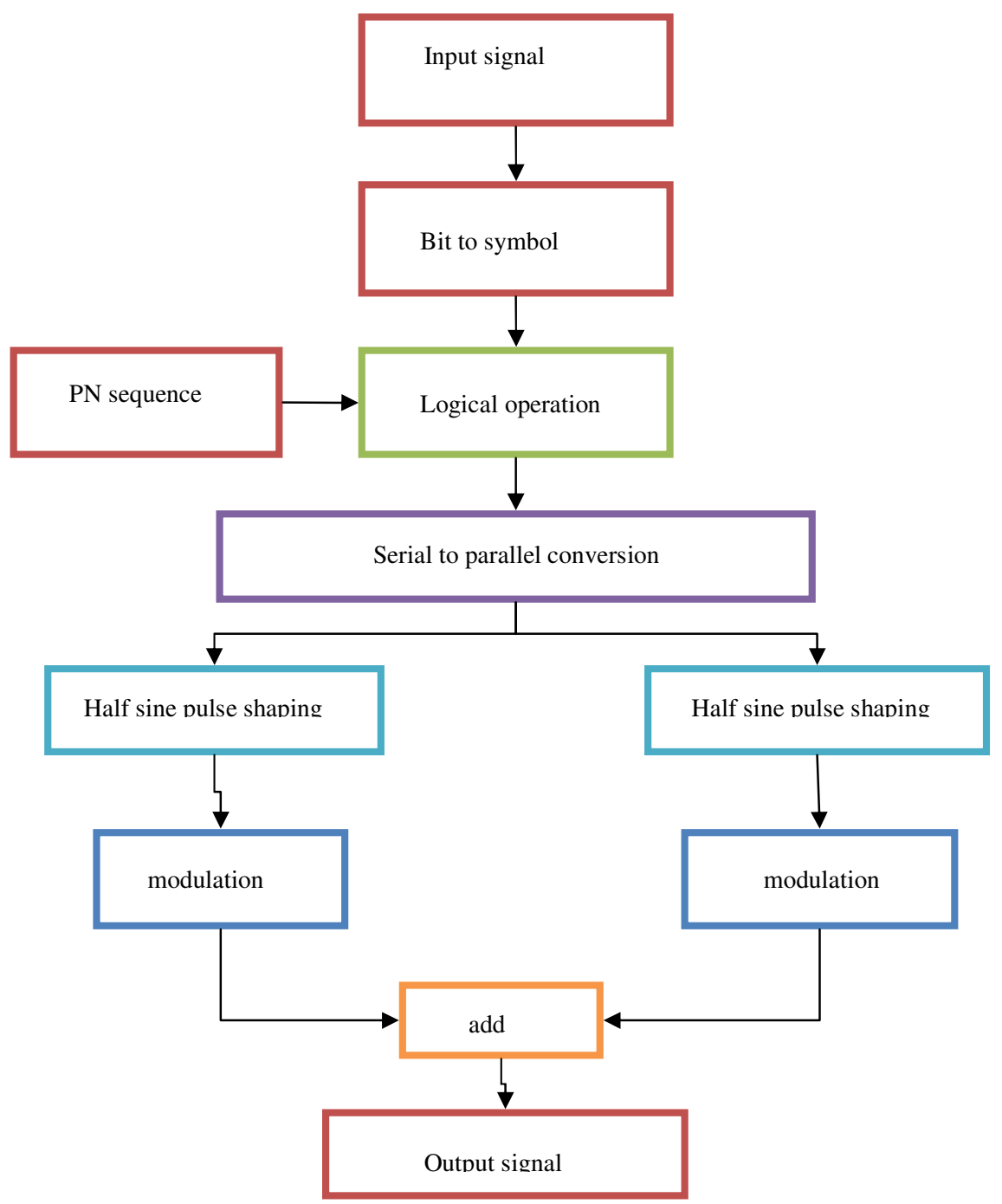

Figure 5. Block diagram of transmitter end of ZigBee

\subsubsection{Receiver End:}

2.Following steps have been done for receiving the data.

Incoming signal is multiplied with inphase and quadrature phase high frequency carrier followed by low pass filter.

The resultant is passed to sample and hold circuit and then comparator that has a fixed threshold value for making a decision.If the value is greater than threshold,it takes the bit as 1 otherwise 0 .The signal is then delayed at inphase side of incoming signal and further both signal processed to parallel to serial conversion.

Now logical operation is done on this signal with PN sequence generator and the data is received.The whole process can be shown with the diagram as in figure 6 . 
International Journal of Computer Networks \& Communications (IJCNC) Vol.6, No.3, May 2014

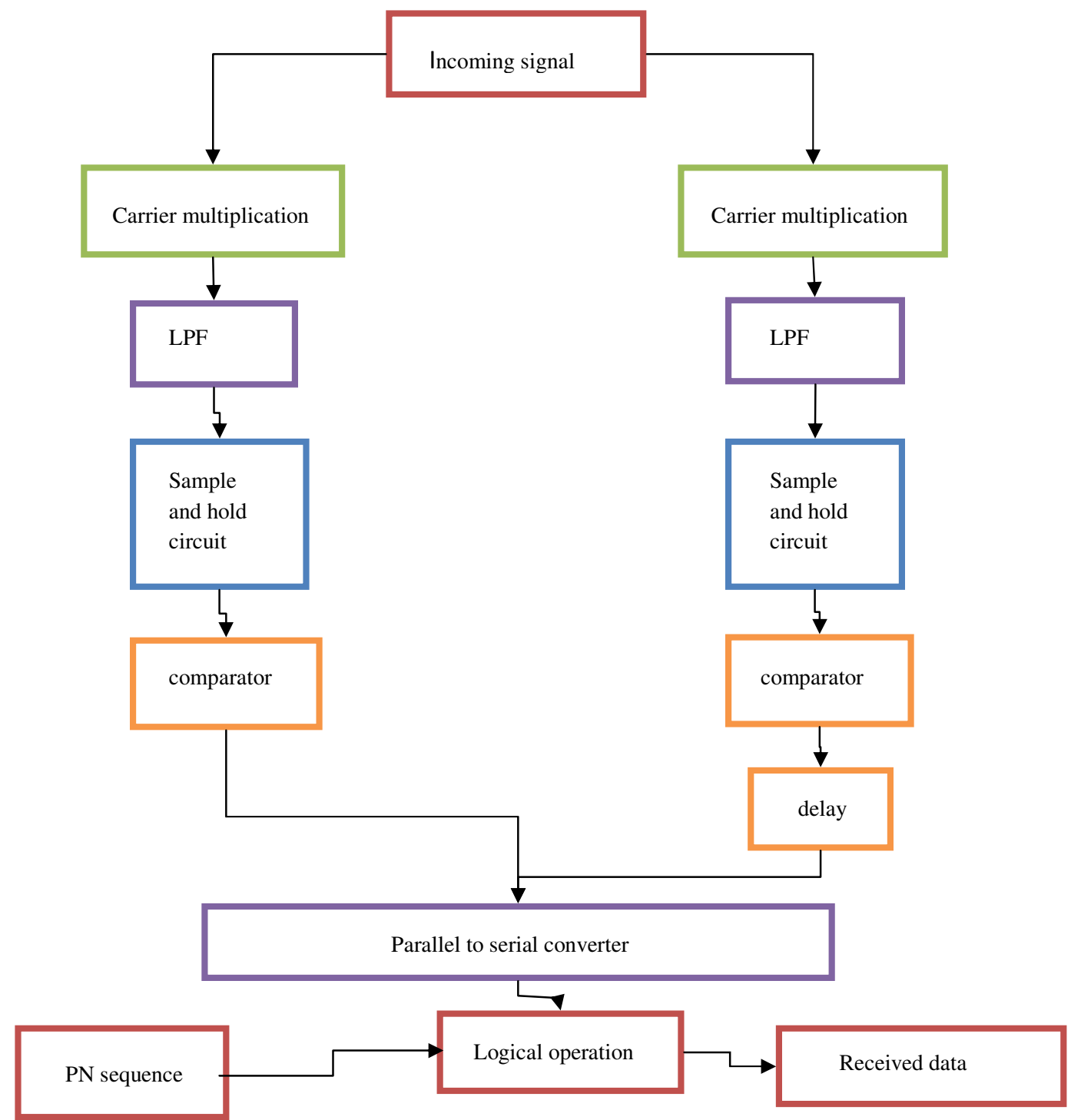

Figure 6. Block diagram of receiver end of ZigBee

\subsubsection{MODULATION TECHNIQUES USED}

\subsubsection{Offset Quadrature Phase Shift Keying}

Offset QPSK and QPSK are same.The similarity between the two is that their power spectral density and error performance is the same.But the differences which makes them different are: 1.There is delay in Q-channel.

2.The pulse train of both the channels are staggered.

3.OQPSK is more power-efficient than QPSK technique since the maximum phase change in the waveform is $\Pi / 2$. 
International Journal of Computer Networks \& Communications (IJCNC) Vol.6, No.3, May 2014

\subsubsection{Minimum Phase Shift Keying}

In place of OQPSK,MSK modulation techniques has been applied next.

The benefits of using MSK are:

1.The baseband waveform of MSK is smoother,that multiplies the quadrature carrier than rectangular waveform of QPSK.

2.The main centre lobe in MSK is 1.5 times wider than QPSK and the side lobes in MSK are relatively smaller in comparision to the main lobe,hence filtering becomes easier.

3. MSK possess phase continuation that is no phase change,while QPSK not.Hence intersymbol interference is reduced.

Minimum shift keying helps orthogonal detection since it allows minimum frequency separation ,called bandwidth.Over any symbol interval,MSK can have one of two possible frequencies:

$$
s(t)=a_{I}(t) \cos \left(\frac{\Pi t}{2 T}\right) \cos (2 \Pi f t)+a_{Q}(t) \sin \left(\frac{\Pi t}{2 T}\right) \sin (2 \Pi f t)
$$

\subsubsection{ADVANTAGES OF ZIGBEE}

Advantages of ZigBee can be summarized as:

1) Power consumption is low, simple implementation.

2) Long Battery life.

3) Device cost and installation cost is low and low maintenance is required.

4) It can handle many devices at a time,Since it provides high density of nodes per network.

5) Simple protocol and has global implementation.

\subsubsection{SIMULATION}

The implementation has been built on Matlab/Simulink using fundamental components in Simulink to demonstrate how reliably complex modulation schemes can be built, cost effectively and efficiently. Where the input bit stream was generated using Bernoulli random generator.And then logical operation is performed with PN sequence.The resulted signal has the data rate of 2Mbps.

After serial to parallel conversion,the signal gets divided into two components,Inphase and Quadrature phase.Then modulation is done with a high frequency $2.4 \mathrm{GHz}$ carrier on the In Phase and Quadrature Phase data stream.Both are then summed up to get the required transmitter output signal.For modulation,two modulation technique have been applied to study the efficient scheme that can be applied in ZigBee transceiver.Then the Bit error rate has been studied for the two.

\section{RESULT AND DISCUSSION}

Different modulation schemes has been applied at transmitter end and receiver end.Those are OQPSK that is offset Quadrature Phase Shift Keying.Second is MSK that is Minimum Shift Keying.Then the bit error rate for these techniques has been calculated and following graph in figure 7 shows the BER comparision. 


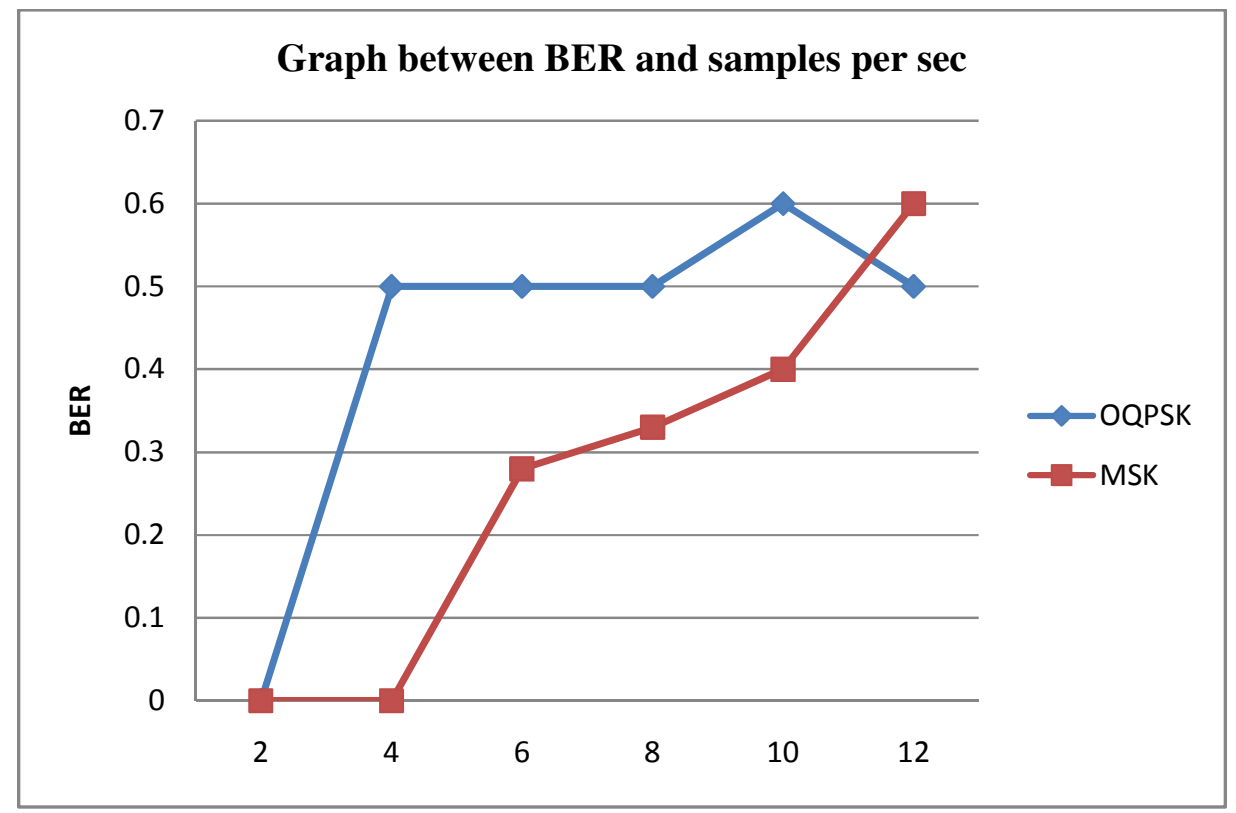

Figure 7. BER comparision between different modulation technique

ZigBee standard is a great solution for wireless sensor network.Using simulation,ZigBee transceiver has been designed for different modulation technique and it has been found that MSK based designing is most promising technology which provides low data rate with low BER \& large acquired area. So, this technology can be used.

\section{APPLICATION}

Bioimpedance measurement using tetrapolar method can be widely used in studying the state of tissues.It can be implemented in skin hydration,cerebral monitoring,dental decay diagnosis and many other health problems.

Due to limitations in other wireless technology such as frequent need of charging,more power consumption,ZigBee is becoming a smart choice for transmitting data.ZigBee technology is programmed in chip form and can be applied to many other fields such as home automation,energy management,industrial plant management etc.

\section{CONCLUSION}

The proposed system integrating the impedance measurement technique and ZigBee enables the remote monitoring of health issues.ZigBee has longer battery life due to low power consumption.Secure and reliable transmission can be achieved through it.ZigBee transceiver based on minimum shift keying modulation technique are better one since in minimum shift keying,bit error rate is lower as compared to other modulation technique and it produce constant envelope carrier signals which have no amplitude and phase varations, hence it will be a more power saving technique.Bioimpedance measurement through traditional methods are time consuming and not safe even.PSD method is also not popular as the use of demodulators causes phase error and complex circuitary hinders its use.Hence tetrapolar method is best among all methods.Due to use of integrated chips, it liberates the traditional methods from the complexity of 
International Journal of Computer Networks \& Communications (IJCNC) Vol.6, No.3, May 2014

design.Its accuracy is goog and it has wide frequency range.Power consumption and design cost is also low.

\section{REFERENCES}

[1] R.Pallas and J.Webster(1993),Bioelectric impedance measurements using synchronous sampling,Biomedical Engineering IEEE,vol.40,issue 8.pp 824-829

[2] M.Min,P.Annus,R.Land,T.Paavle,E.Hardle and R.Ruus(2007),Bioimpedance monitoring of tissue transplants,Instrumentation and Measurement Technology Conference proceedings,pp1-4.

[3] S.Kun,B.Ristic,R.Peura and R.Dun(1999),Real time extraction of tissue impedance model parameters for electrical impedance spectrometer,Medical and Biological Engineering and Computing,springer vol.37,issue4, pp 428-432.

[4] S. Kun and R. A. Peura(1994),Tissue ischemia detection using impedance spectroscopy,Engineering in Medicine and Biology Society,Proceedings of the 16th Annual International Conference of the IEEE,vol.2,pp 868-869.

[5] P.Rohita,P.Ranjeet Kumar,N.Adinarayana and T.Venkat Narayana Rao(2012),Wireless networking through ZigBee technology,International Journal Of Advance Research in Computer Science and Software Engineering,vol.2 issue7,pp 49-54.

[6] W.Wang,G.He and J.Wan(2011),Research On ZigBee Wireless Communication Technology,Electrical And Control Engineering International Conference Yichang,pp1245-1249.

[7] H.Chen and C.Zhang(2012).The result and implement of ZigBee technology for building wireless voice network,Measurement Information and Control,vol.2,pp,576-580.

[8] S.Bamber and A.K.Sharma(2010),Performance trade off with modulation $\mathrm{n}$ 802.15.4 WPAN for wireless sensor networks, International Journal Of Computer Networks and Communication, Vol.2,No.6,pp 77-87.

[9] S.S.Riaz Ahamed(2005),Role of ZigBee technology in future data communication system,Journal Of Theoretical And Applied Information Technology,pp129-135.

[10] Varshaney and A.Sharma(2013),Design and simulation of ZigBee transceiver system using Matlab,International Journal Of Engineering Trends and Technology,vol.4,issue4,pp 1316-1319.

[11] J.Songer(2001),Tissue ischemia monitoring using impedance spectroscopy:Clinical evaluation,in Biomedical Engineering,Worcester Polytechnic Institute,MSc.

[12] S.Ouni and Z.Ayoub(2013),Predicting communication delay and energy consumption for IEEE 802.15.4/ZigBee wireless sensor networks,International Journal Of Computer Networks and Communication IJCNC, vol.5,No.1,pp 141-152.

\section{AUTHORS}

Ruchita Pandey received her B.Tech Degree from department of Electronics And Communcation Engineering from Krishna Institute Of Engineering and Technology Ghaziabad in 2011.She is persuing M.Tech from the Department of Electronics and Communication SHIATS,Allahabad.Her main research interest includes Communication System Engineering,Biomedical Engineering and Signal Processing.

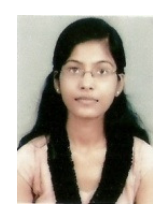


Mukesh Kumar is working as an Asst. Prof. in Electronics \& Communication Engineering department,SHIATS.He has done M.Tech in Advanced Communication System En gineering from SHIATS, Allahabad in 2010.Signal processing and Microwave Engineering are his main area of research.

A.K. Jaiswal is working as a Proffesor and is Head of ECE Department at SHIATS. He has done M.Sc. in Technology,Electronic \& Radio Engineering. from Allahabad University in 1967.Various projects \& research at undergraduate \& postgraduate level are guided by him.His experience is more than 35years in Industrial, research \& Teaching.Optical Networks and satellite communication are his main area of research.

Rohini Saxena is working as an Asst. Prof. in the Department of Electronics \& Communication Engineering in SHIATS, Allahabad.She has done M.Tech. Degree in Advanced Communication System Engineering from SHIATS, Allahabad in 2009.Digital Communication,Microwave Engineering,Wireless Sensor Network,Computer Networks and Mobile Communication are her research fields.
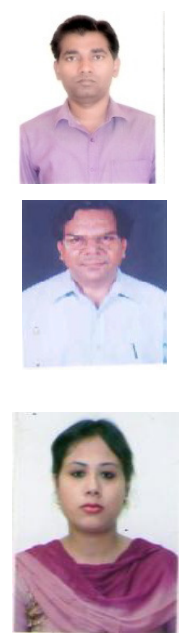